\title{
ANALISIS KESESUAIAN PENGGUNAAN LAHAN TERHADAP POLA RUANG DI DAERAH ALIRAN SUNGAI BIALO
}

\author{
Andang Suryana Soma ${ }^{1)}$ Nirmala Reski ${ }^{2)}$, Usman Arsyad ${ }^{1)}$, Wahyuni' ${ }^{1)}$, dan \\ Budirman Bachtiar ${ }^{1)}$ \\ 1) Jurusan Kehutanan, Fakultas Kehutanan, Universitas Hasanuddin \\ Jalan Perintis Kemerdekaan KM 10, Makassar \\ 2) Laboratorium Pengelolaan Daerah Aliran Sungai, Fakultas Kehutanan, Universitas Hasanuddin \\ Jalan Perintis Kemerdekaan KM 10, Makassar \\ Korespondesi: suryaandang @ gmail.com
}

\begin{abstract}
ABSTRAK:
Penelitian ini bertujuan untuk menganalisis penggunaan lahan dan mengidentifikasi kesesuaian penggunaan lahan dengan pola ruang di Daerah Aliran Sungai Bialo serta menentukan arahan penggunaan lahan jika terjadi ketidaksesuaian antara penggunaan lahan dengan rencana tata ruang wilayah di DAS Bialo. Jenis data yang dikumpulkan ada dua yaitu data primer berupa data penggunaan lahan dan data sekunder yaitu peta Rencana Tata Ruang Wilayah (RTRW). Data yang diperoleh dianalisis dengan interpretasi, uji akurasi citra dan di overlay untuk penentuan kesesuaian penggunaan lahan dengan pola ruang. Berdasarkan hasil analisis kesesuaian penggunaan lahan dengan pola ruang diperoleh bahwa penggunaan lahan yang sesuai dengan pola ruang sebesar $87,80 \%$ dan yang tidak sesuai sebesar 12,20\%. Arahan penggunaan berupa Reboisai, Hutan Desa, Agroforestry, Multi purpose tree species (MPTS) pada penggunaan lahan hutan lahan kering sekunder, pertanian lahan kering, Pemukiman. Penanaman tanaman penutup tanah dan penguat teras pada lahan sawah dan suksesi alami pada penggunaan lahan semak belukar
\end{abstract}

Kata Kunci: Kesesuaian, Penggunaan lahan, Pola Ruang, DAS Bialo

\section{ABSTRACT:}

This research aims to analyze the land use and identify the suitability of the land use plan of space in Bialo Watersheds and determine the direction of land use if there is a mismatch between the land use with the regional plan in Bialo watersheds. The data were collected in primary data was the land use and secondary data of regional plan. The data were analyzed with interpretation, test accuracy, and conformity determination for land use overlay with the plan space. Based on the analysis of land-use suitability with the plan space, a land-use plan is acquired that fits the area of $87.80 \%$ and is not following $12.20 \%$. Use of the referral in the form of reboisation, the village forests, agroforestry, multi-purpose tree species (MPTS) on dry land forest land use, agricultural secondary dry land, settlements. Planting cover crops and soil reinforcement terrace on paddy fields and natural succession on land use scrub.

Keywords: Suitability, Landuse, Regional Plan, Bialo Watershed 


\section{PENDAHULUAN}

Laju pertumbuhan penduduk akan berpengaruh terhadap kebutuhan lahan, namun karena ketersediaan lahan terbatas menyebabkan terjadinya alih fungsi lahan atau perubahan penggunaan lahan. Alih fungsi lahan yang paling disoroti saat ini adalah alih fungsi lahan berhutan. Alih fungsi lahan hutan merupakan perubahan fungsi pokok hutan menjadi kawasan non hutan seperti, pemukiman, areal pertanian dan perkebunan. Alih fungsi lahan dalam arti perubahan penggunaan lahan, pada dasarnya tidak dapat dihindarkan dalam pelaksanaan pembangunan. Masalah ini bertambah berat dari waktu ke waktu sejalan dengan meningkatnya luas areal hutan yang dialihfungsikan menjadi lahan usaha. Hal inilah yang menyebabkan terjadinya ketidaksesuaian penggunaan lahan dengan rencana peruntukannya sehingga akan berdampak pada kerusakan lahan. kerusakan lahan akan menurunkan produktifitas lahan sehingga berdampak pada luasan lahan kritis yang semakin meningkat dan akan menyebakan terjadinya penurunan daya dukung pada Daerah Aliran Sungai (DAS).

Turunnya daya dukung DAS dicirikan oleh terjadinya erosi dan sedimentasi, banjir pada musim hujan dan kekeringan pada musim kemarau serta penurunan produktivitas lahan. Kejadian seperti ini terjadi hampir di seluruh wilayah DAS dari hulu sampai hilir

Lokasi penelitian yang berada di DAS Bialo secara administratif terletak di dua kabupaten yaitu Kabupaten Bantaeng dan Kabupaten Bulukumba Provinsi Sulawesi Selatan yang berada di $05^{0} 21^{\prime} 0^{\prime \prime}-05^{0} 34^{\prime} 0^{\prime \prime}$ Lintang Setatan dan $119^{0} 55^{\prime} 0^{\prime \prime}-120^{0} 13^{\prime} 0^{\prime \prime}$ Bujur Timur. DAS Bialo yang memiliki luas $114 \mathrm{~km} 2$ dan berada pada ketinggian antara 0 - 1000 meter di atas permukaan laut dengan luas $10.948,15$ ha (Tanika et al. 2013). Hasil pengamatan awal terhadap Kondisi penggunaan lahan DAS Bialo secara keseluruhan berupa Hutan Lahan Kering Primer, Hutan Lahan Kering Sekunder, Pertanian Lahan Kering, Pemukiman, Sawah, Semak Belukar dan Tambak. Hasil penelitian di lapangan terhadap pola penggunaan lahan tersebut menunjukkan bahwa banyak terjadi ketidaksesuaian penggunaan lahan di lapangan dengan pola ruang wilayah, sehingga perlu dilakukan arahan penggunaan lahan.

Berdasarkan uraian tersebut, maka perlu dilakukan penelitian mengenai Kesesuaian penggunaan lahan dengan pola ruang wilayah. Hal ini diharapkan dapat melalui penelitian ini bisa mengetahui penggunaan lahan di DAS Bialo, mengidentifikasi kesesuaian penggunaan lahan dengan pola ruang di DAS Bialo, dan menentukan arahan penggunaan lahan jika terjadi ketidaksesuaian antara penggunaan lahan dengan rencana tata ruang wilayah di DAS Bialo. 


\section{BAHAN DAN METODE}

Penelitian ini dilaksanakan di DAS Bialo dan Laboratorium Pengelolaan DAS Universitas Hasanuddin. Alat yang digunakan dalam penelitian ini meliputi, Receiver GPS, alat tulis menulis, kamera, Abney Level dan perangkat komputer dengan aplikasi SIG. Bahan yang digunakan meliputi Citra Landsat 8 tahun 2018, Peta Batas DAS Bialo, Peta Kelerengan dan peta RTRW Kabupaten Bantaeng dan Bulukumba.

\section{Metode Pengumpulan Data}

1. Pengumpulan Data Primer

a) Mengidentifikasi jenis-jenis penutupan lahan.

b) Penetapan titik koordinat sampling yang di survei didasarkan pada peta penggunaan lahan . Peta penggunaan lahan tersebut lalu dioverlay dengan peta pola ruang untuk menghasilkan peta kesesuaian. Penentuan titik yang menjadi pewakil disetiap penggunaan lahan menggunakan prinsip purposive sampling (keterwakilan) pada peta kesesuaian dengan mempertimbangkan faktor aksesibilitas dari setiap penggunaan lahan yang dipilih dan melihat luasan dari masing-masing penggunaan lahan tersebut. Titik sampel yang telah ditentukan dicatat dan dimasukkan data koordinatnya ke dalam GPS.

c) Survey dan pengambilan data lapangan (cross check) sesuai dengan titik yang telah ditentukan pada peta kerja dengan mengamati keadaan dan pola penggunaan lahan.

d) Analisis data dengan mengelola data lapangan dan mengadakan perbaikan / koreksi.

2. Pengumpulan Data Sekunder

Merupakan data atau informasi yang diperoleh dari berbagai instansi serta badan pemerintah yang terkait yakni peta Rencana Tata Ruang Wilayah Kabupaten (RTRW)

3. Analisis Data

a) Interpretasi Citra

Membuat peta penutupan lahan yang berasal dari citra satelit dengan menggunakan citra landsat 8 Path 114 Row 62 bulan September tahun 2018. Citra tersebut diunduh melalui website http://earthexplorer.usgs.gov. kemudian di interpretasi yang diawali dengan penggabungan pita warna (composite band). Selanjutnya dilakukan digitasi on screen, yaitu mendigitasi langsung citra tersebut dengan mengandalkan visual. Kelas penggunaan lahan ditetapkan berdasarkan pola dan karakteristik (rona, warna, dan tekstur) pada citra tersebut.

b) Uji Akurasi 
Untuk menguji keakuratan interpretasi citra maka dilakukan uji akurasi klasifikasi citra yang bertujuan untuk mengetahui sejauh mana keakuratan interpretasi citra yang telah dilakukan menurut (Thomas M. Lillesand 1993). Proses ini disebut dengan overall accuracy dengan persamaan sebagai berikut :

$$
\mathrm{OA}=\frac{x}{N} \times 100 \%
$$

dimana :

$x=$ Jumlah nilai diagonal matriks

$N \quad=$ Jumlah sampel matriks

c) Penentuan Kesesuaian

Kesesuaian penggunaan lahan ditentukan dengan metode analisis spasial menggunakan aplikasi software SIG (Sistem Informasi Geografis). Penentuan kesesuaian bentuk penggunaan lahan didasarkan pada fungsi kawasan yang ditetapkan dalam Undangundang Republik Indonesia Nomor 26 Tahun 2007 tentang rencana pola ruang. Rencana pola ruang yang dimaksud meliputi:

a. Peruntukan ruang untuk kawasan lindung

b. Peruntukan ruang untuk kawasan budidaya

d) Arahan Penggunaan Lahan

Arahan penggunaan lahan yang tidak sesuai dengan pola ruang pada DAS Bialo diarahkan dengan melihat kondisi lapangan dan diberikan arahan yang sesuai dengan konservasi tanah dan air dengan mempertimbangkan kesejahteraan masyarakat dan kelestarian lingkungan misalkan Hutan Lindung dan Hutan Produksi. Pada Kawasan Hutan Lindung diarahkan untuk mempertahankan kawasan hutan agar tetap berfungsi sebagai konservasi dan Kawasan Hutan Produksi diarahkan untuk Hutan Kemasyarakatan (HKm) dengan system agroforestry dan Kawasan Budidaya diarahkan untuk melakukan system agroforestry.

\section{HASIL DAN PEMBAHASAN}

Hasil interpretasi citra dan dari hasil observasi lapangan terhadap penggunaan lahan di DAS Bialo maka diketahui terdapat 7 kategori penggunaan lahan yang selanjutnya dapat dilihat pada Tabel 1. 
Tabel 1. Klasifikasi tutupan lahan di DAS Bialo Tahun 2019

\begin{tabular}{|l|l|r|r|}
\hline No. & Penggunaan Lahan & \multicolumn{1}{|l|}{ Luas (ha) } & \multicolumn{2}{l|}{$\begin{array}{l}\text { Presentasi } \\
(\%)\end{array}$} \\
\hline 1 & Hutan Lahan Kering Primer & $2.126,06$ & 19,44 \\
\hline 2 & Hutan Lahan Kering Sekunder & $1.189,80$ & 10,88 \\
\hline 3 & Pemukiman & 605,20 & 5,53 \\
\hline 4 & Pertanian Lahan Kering & $5.231,70$ & 47,84 \\
\hline 5 & Sawah & $1.697,73$ & 15,53 \\
\hline 6 & Semak Belukar & 83,31 & 0,76 \\
\hline 7 & Tambak & 1,60 & 0,01 \\
\hline & Total & $10.934,40$ & 100,00 \\
\hline
\end{tabular}

Berdasarkan Tabel 1 luas hutan di DAS Bialo sebesar 30,32 \% , merujuk pada Undangundang Nomor 41Tahun 1999 luas hutan sudah memenuhi target minimal luas hutan sebesar $30 \%$ dari luas daerah aliran sungai atau pulau dengan sebaran yang proporsional. Hal ini juga diungkapkan oleh Tanika et al. 2013 pada penelitiannya di DAS Bialo 10 tahun terakhir mengenai kondisi hutan yang masih stabil. Namun perlu kita ketahui bahwa setiap tahunnya penduduk dipastikan akan selalu meningkat artinya semakin bertambahnya penduduk maka permintaan akan lahan juga meningkat sehingga luas lahan hutan yang saat ini masih stabil sewaktu-waktu akan berkurang luasannya.

Berdasarkan hasil pengecekan lapangan (ground check), terdapat beberapa titik penggunaan lahan yang ditemukan berbeda dengan hasil interpretasi citra. Perbedaan ini terjadi karena tingkat ketelitian dan resolusi citra yang rendah sehingga mengakibatkan suatu objek tidak bisa dibedakan secara pasti. Contohnya saja pada peta hasil interpretasi berupa hutan lahan kering sekunder beberapa titik yang dikunjungi ternyata sudah berubah menjadi pertanian lahan kering. Hasil klasifikasi penggunaan lahan tahun 2018 kemudian dilakukan uji keakuratan hasil interpretasi citra. Uji ketelitian dilakukan dengan menggunakan tabel confusion matriks yang bertujuan untuk mengetahui persentase tingkat kepercayaan dari hasil interpretasi citra landsat 8 tahun 2018. Jumlah titik sampel yang sesuai hasil interpretasi dengan keadaan dilapangan dibagi dengan jumlah titik sampel seluruhnya lalu dikali 100 . Hasilnya akan menunjukkan persentase tingkat keakuratan interpretasi citra yang telah dilakukan. Tabel confusion matriks klasifikasi penggunaan tahun 2018 dapat dilihat pada Tabel 2. 
Tabel 2. Matriks Confusion Titik Sampel Klasifikasi tutupan lahan Tahun 2018

\begin{tabular}{|c|c|c|c|c|c|c|c|c|c|}
\hline \multirow{2}{*}{\multicolumn{2}{|c|}{$\begin{array}{c}\text { Penggunaan } \\
\text { Lahan }\end{array}$}} & \multicolumn{8}{|c|}{ Data Lapangan Februari Tahun 2018} \\
\hline & & \multirow{2}{*}{$\frac{P 1}{6}$} & \multirow{2}{*}{$\begin{array}{r}\mathrm{P} 2 \\
4\end{array}$} & \multirow[t]{2}{*}{ P3 } & \multirow[t]{2}{*}{ P4 } & \multirow[t]{2}{*}{ P5 } & \multirow[t]{2}{*}{ P6 } & \multirow[t]{2}{*}{ P7 } & \multirow{2}{*}{$\begin{array}{c}\text { Jumlah } \\
10\end{array}$} \\
\hline \multirow{8}{*}{ 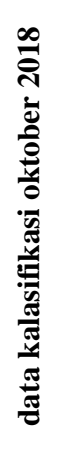 } & P1 & & & & & & & & \\
\hline & $\mathrm{P} 2$ & & 11 & 1 & & & & & 12 \\
\hline & P3 & & & 45 & 1 & 3 & & & 49 \\
\hline & $\mathrm{P} 4$ & & & & 29 & 1 & & & 30 \\
\hline & P5 & & & & 2 & 32 & & 1 & 35 \\
\hline & P6 & & & & & & 5 & & 5 \\
\hline & $\mathrm{P} 7$ & & & & & & & 1 & 1 \\
\hline & Jumlah & 6 & 15 & 46 & 32 & 36 & 5 & 2 & 142 \\
\hline
\end{tabular}

Keterangan :

P1 = Hutan Lahan Kering Primer

$\mathrm{P} 5=$ Sawah

P2 = Hutan Lahan Kering Sekunder

P3 = Pertanian Lahan Kering

P6 = Semak Belukar

P4 = Pemukiman

$\mathrm{P7}=$ Tambak

$$
\begin{aligned}
\mathrm{OA}= & \frac{\text { Jumlah titik yang sesuai }}{\text { Jumlah titik keseluruhan }} \times 100 \% \\
= & \frac{129}{142} \times 100 \% \\
& =90,84 \%
\end{aligned}
$$

Klasifikasi penggunaan lahan tahun 2018 pada Tabel cunfusion matriks menunjukkan 129 titik sesuai dengan kondisi di lapangan dan yang tidak sesuai yaitu 13 titik. Berdasarkan hasil tersebut diperoleh tingkat ketelitian hasil interpretasi yang dilakukan yaitu 90,84\% maka hasil interpretasi yang dilakukan dapat diterima. Hal tersebut sesuai dengan pernyataan Thomas $\mathrm{M}$. Lillesand (1993), bahwa klasifikasi citra dapat diterima yaitu dengan tingkat ketelitian minimal $85 \%$.

\section{Kesesuaian Penggunaan Lahan Tahun 2018 Terhadap Pola Ruang 2012-2032 di DAS Bialo}

Peta penggunaan lahan yang berasal dari interpretasi citra selanjutnya di overlay dengan peta pola ruang. Hal tersebut dilakukan untuk mengetahui penggunaan lahan yang sesuai dengan Rencana Tata Ruang Wilayah dan penggunaan lahan yang tidak sesuai di DAS Bialo dapat dilihat pada Gambar 1. 


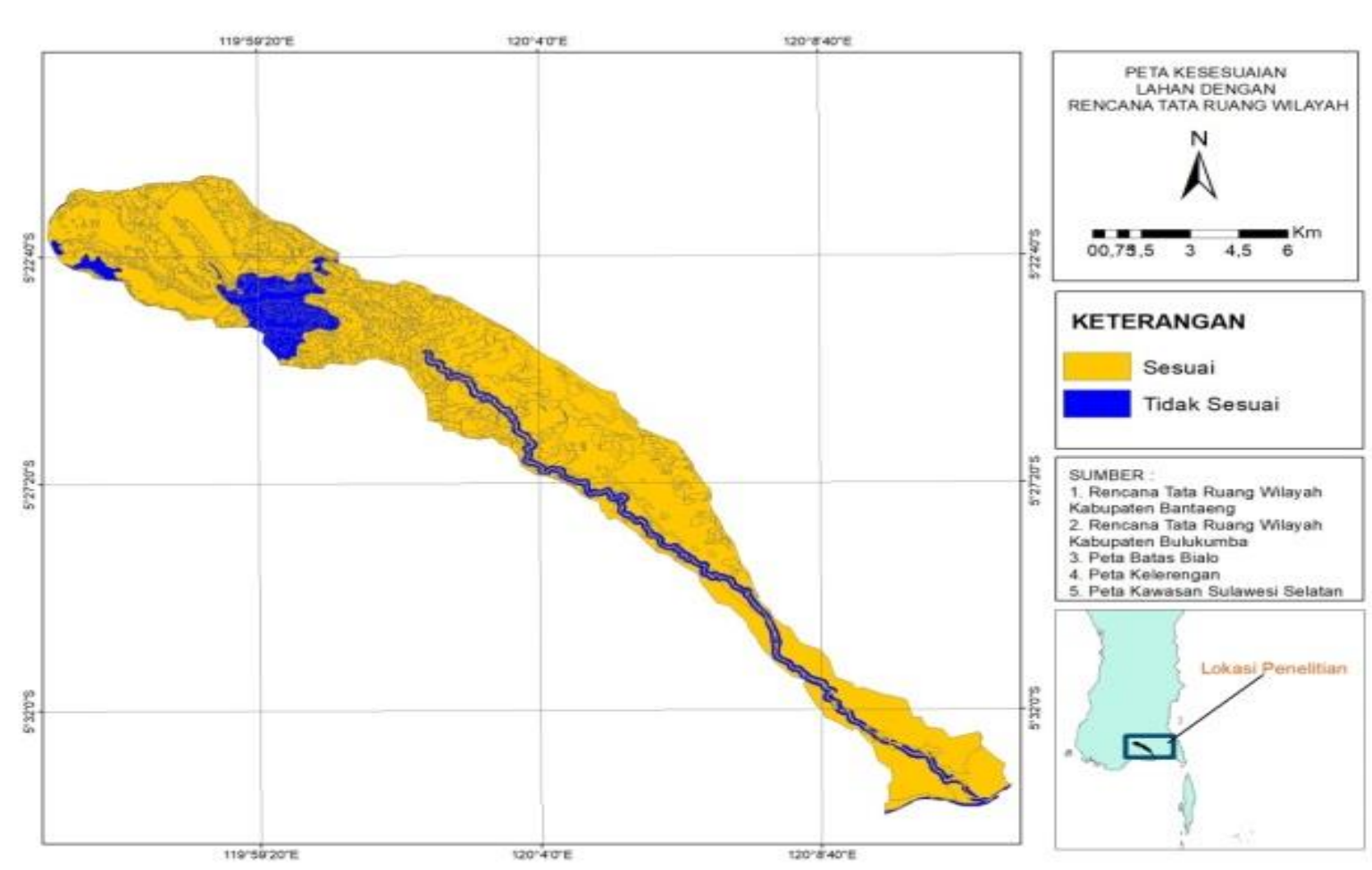

Gambar 1. Peta Kesesuaian tutupan lahan 2018 dengan RTRW 2012-2032 RTRW di DAS Bialo

Hasil interpretasi citra yang di overlay dengan peta RTRW kemudian disajikan dalam matriks. Matriks tersebut dibuat untuk lebih mudah mengetahui luasan penggunaan lahan yang sesuai dan yang tidak sesuai dengan pola ruang seperti yang disajikan pada Tabel 3.

Tabel 3. Matrik Kesesuain Tutupan Lahan Tahun 2018 dengan RTRW 2012-2032 di DAS Bialo

\begin{tabular}{|c|c|c|c|c|c|c|c|c|c|c|c|c|c|c|c|c|}
\hline & & \multicolumn{14}{|c|}{ Luas Pola Ruang (ha) } & \multirow{3}{*}{$\begin{array}{l}\text { Total } \\
\text { (ha) }\end{array}$} \\
\hline & & \multicolumn{2}{|c|}{ Hutan Lindung } & \multicolumn{2}{|c|}{$\begin{array}{c}\text { Pertanian Lahan } \\
\text { Kering }\end{array}$} & \multicolumn{2}{|c|}{ Permukiman } & \multicolumn{2}{|c|}{ Perkebunan } & \multicolumn{2}{|c|}{$\begin{array}{c}\text { Pertanian } \\
\text { Lahan Basah }\end{array}$} & \multicolumn{2}{|c|}{$\begin{array}{c}\text { Sempadan } \\
\text { pantai }\end{array}$} & \multicolumn{2}{|c|}{$\begin{array}{c}\text { Sempadan } \\
\text { Sungai }\end{array}$} & \\
\hline & & Sesuai & $\begin{array}{l}\text { Tidak } \\
\text { Sesuai }\end{array}$ & Sesuai & $\begin{array}{c}\text { Tidak } \\
\text { Sesuai }\end{array}$ & Sesuai & $\begin{array}{l}\text { Tidak } \\
\text { Sesuai }\end{array}$ & Sesuai & $\begin{array}{l}\text { Tidak } \\
\text { Sesuai }\end{array}$ & Sesuai & \begin{tabular}{|l|} 
Tidak \\
Sesuai
\end{tabular} & Sesuai & $\begin{array}{c}\text { Tidak } \\
\text { Sesuai }\end{array}$ & Sesuai & $\begin{array}{c}\text { Tidak } \\
\text { Sesuai }\end{array}$ & \\
\hline \multirow{7}{*}{ 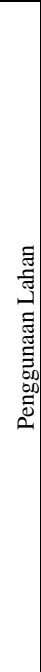 } & $\begin{array}{l}\text { Hutan } \\
\text { Lahan } \\
\text { Kering } \\
\text { Primer }\end{array}$ & 2146,17 & & & 16,51 & & & & & & & & & & & 2162,68 \\
\hline & $\begin{array}{l}\text { Hutan } \\
\text { Lahan } \\
\text { Kering } \\
\text { Sekunde } \\
\mathrm{r}\end{array}$ & 615 & & & 650,27 & & & & & & & & & & & 1265,62 \\
\hline & $\begin{array}{l}\text { Pertania } \\
\text { n Lahan } \\
\text { Kering }\end{array}$ & & & 2060,96 & & 2639,92 & & 70,14 & & & & & & & 368,19 & 5139,21 \\
\hline & Sawah & & & & & & & & & 1495,72 & & & 181,23 & & 1,18 & 1678,13 \\
\hline & $\begin{array}{l}\text { Pemuki } \\
\text { man }\end{array}$ & & 0,46 & 535,81 & 5,04 & & & & & & & & 79,91 & & & 621,22 \\
\hline & $\begin{array}{l}\text { Semak } \\
\text { Belukar }\end{array}$ & & 79,95 & & & & & & & & & & & & & 79,95 \\
\hline & Tambak & & & & & & & & & & & & 1,6 & & & 1,60 \\
\hline & Total & 2761,51 & 80,41 & 2596,77 & 671,83 & 2639,92 & 0 & 70,14 & 0 & 1495,72 & 0 & 0 & 262,74 & 0 & 369,37 & 10948,41 \\
\hline
\end{tabular}


Luasan masing-masing penggunaan lahan yang sesuai dan yang tidak sesuai dengan pola ruang seperti pada Tabel 3 adalah sebesar $87,8 \%$ yang sesuai, sedangkan yang tidak sesuai seluas $12,2 \%$. Penyebab terjadinya ketidaksesuaian diantaranya pertumbuhan penduduk yang membutuhkan luasan lahan untuk berbagai kepentingan pembangunan, dan peta penggunaan lahan yang digunakan tahun 2018 sedangkan untuk pola ruang sendiri tahun 2012-2032 artinya bahwa sangat wajar jika terjadi ketidaksesuaian karena penelitian tidak dilakukan diakhir masa berlakunya pola ruang. Hal ini sejalan dengan penelitian yang telah dilakukan Lubis, Suprayogi, and Hani'ah (2013) bahwa faktor yang menyebabkan ketidaksesuaian penggunaan lahan yaitu Perbedaan acuan dalam pembuatan peta akan menimbulkan ketelitian yang berbeda, hal ini akan berpengaruh pada luasan, letak dan bentuk objek yang diamati, Pengaruh pertumbuhan pembangunan yang belum mencapai target di wilayah yang telah di rencanakan, sehingga pada saat dilakukannnya penelitian, beberapa daerah yang telah direncanakan untuk fungsi tertentu belum terwujud sebagaimana mestinya. Penelitiannya menggunakan peta Rencana Tata Ruang Wilayah tahun 2000-2010, sedangkan data Tutupan Lahan yang digunakan adalah Tutupan Lahan tahun 2007. Jadi penelitian yang dilakukan bukan di akhir masa berlakunya Rencana Tata Ruang yang digunakan, oleh sebab itu sangat wajar jika diperoleh ketidaksesuaian yang cukup besar dalam analisis ini.

Hutan lahan kering sekunder merupakan kawasan hutan lindung yang tumbuh berkembang pada habitat lahan kering yang dapat berupa hutan dataran rendah, perbukitan dan pegunungan, atau hutan tropis hutan dataran tinggi, yang masih kompak dan telah mengalami intervensi manusia. Namun di lapangan telah terjadi konversi lahan menjadi pertanian lahan kering dengan komoditas tanaman cengkeh (Syzygium aromaticum), kopi (Coffea arabica), coklat (Theobroma cacao), pisang (Musa sp), ubi kayu (Manihot esculenta), dan keladi (Caladium sp). Lahan yang ditanami tumbuhan tersebut berada pada kondisi lahan yang curam bahkan sangat curam yaitu diatas kemiringan $35 \%$ - >45\%. Berdasarkan Rencana Tata Ruang Wilayah penggunaan pertanian lahan kering dianggap tidak sesuai karena masuk pada kawasan lindung yang berfungsi untuk melindungi kawasan bawahannya sebagai daerah resapan air yang berada pada bagian hulu DAS Bialo. Berdasarkan Tabel 4 penggunaan hutan lahan kering sekunder memiliki luas sebesar 1189,8 ha atau sekitar 10,88 \% dari total keseluruhan DAS.

Areal pemukiman juga menjadi salah satu penggunaan lahan yang tidak sesuai dengan RTRW dikarenakan pemukiman tersebut masuk dalam kawasan lindung. Terdapat dua titik survey pada penggunaan lahan pemukiman yang tidak sesuai dengan RTRW. Kondisi pemukiman yang berada pada hutan lindung dengan kemiringan 30-45 \%. Terlihat pada Tabel 3 bahwa penggunaan lahan pemukiman yang tidak sesuai hanya sekitar 0,46 ha sedangkan hasil 
survey lapangan luasannya mencapai 83,04 ha pada kawasan lindung. Namun karena tingkat ketajaman atau resolusi citra yang rendah sehingga suatu objek tidak bisa diamati secara pasti. Titik yang lain berada di bantaran sungai Bialo yang menjadi lokasi pemukiman masyarakat tanpa memikirkan dampak yang akan diakibatkan dari pembangunan tersebut. Bangunan tersebut sangat dekat dengan sungai sehingga penduduk yang ada disekitar sungai tersebut membuang limbah rumah tangga ke sungai dan mengakibatkan pencemaran lingkungan sehingga mengurangi kualitas air yang ada di sungai tersebut.

Pertanian lahan kering di DAS Bialo merupakan penggunaan lahan terbesar yang umumya digunakan masyarakat Bulukumba dengan luas 5231,7 (47,84 \%). Pertanian lahan kering berada pada kemiringan lereng dari datar hingga curam. Persentase luas penggunaan lahan 47,84 \% sebagian masuk dalam kawasan hutan dengan luas 9,34 \%. Hal ini terjadi karena luas lahan terbatas sehingga kawasan hutan pun dirambah untuk memenuhi kebutuhan hidup meskipun pada lereng yang curam. Pada daerah yang curam yang digunakan untuk pertanian ini merupakan daerah yang sangat rawan terjadinya tanah longsor (Fadilah, Arsyad, and Soma 2019).

Penggunaan pertanian lahan kering umumnya ditanami dengan tanaman semusim berupa jagung, padi, pisang dan berbagai macam sayur mayur sedangkan tanaman tahunan berupa cengkeh, durian, rambutan, kopi dan nangka. Tumbuhan yang paling mendominasi pada penggunaan lahan pertanian lahan kering adalah cengkeh dan kopi. Hampir disetiap penggunaan lahan tersebut ditanami dengan cengkeh dan kopi karena cengkeh dan kopi sangat menguntungkan bagi masyarakat terutama dari aspek ekonomi. Penelitian (Hilmanto 2012) menemukan bahwa tanaman cengkeh dan kopi dapat meningkatkan pendapatan dan keuntungan bagi petani maksimal sebesar Rp.122.056.970,00 tiap tahun dalam satu hektar.

Hasil penelitian menunjukkan bahwa sawah di DAS Bialo sebagian besar berada pada kelerengan (0-8 \% - 8-15\%) dan sebagian kecil di kemiringan lereng 25-45 \% dan terletak di sekitar sungai. Sawah tersebut sebagian terletak didalam kawasan lindung karena berada pada sempadan sungai. Diperkirakan 50\% dari luas sawah yang berada pada kemiringan 0-15\% berada dalam kawasan lindung. Penerapan teknik konservasi tanah dan air di sekitar sungai itu harus benar agar sedimennya tidak langsung masuk ke sungai tetapi tertahan pada saluransaluran teras yang bagus itu. (Asyad 2010) menyatakan bahwa teras bangku dapat berfungsi mengurangi panjang lereng dan menahan air, sehingga mengurangi kecepatan dan jumlah aliran permukaan, dan memungkinkan penyerapan air oleh tanah. Sawah banyak dimanfaatkan masyarakat untuk memenuhi kebutuhan sehari-hari. Sawah-sawah tersebut banyak yang tidak 
sesuai dengan RTRW karena berada pada sempadan sungai yang merupakan kawasan lindung. Hal ini dapat mengakibatkan terjadinya longsor di sekitar sungai. Terbatasnya lahan menyebabkan penduduk memaksimalkan luas lahan di sekitar sungai tanpa memperhatikan pelestarian sumberdaya alam.

Penggunaan lahan semak belukar memiliki beberapa jenis vegetasi yaitu pohon aren, bambu, jambu biji, dan beberapa tumbuhan bawah lainnya. Luas penggunaan lahan semak belukar sebesar 83,31 (0.73\%). Penggunaan lahan semak belukar ini tidak sesuai karena berada pada kawasan lindung dan jumlah pohonnya yang sedikit. Memperkaya tanaman di areal ini dengan tanaman serbaguna yang tidak di panen akan lebih meningkatkan perannya sebagai kawasan lindung.

\section{Arahan Penggunaan Lahan}

Hutan lahan kering sekunder pada DAS Bialo yang dimaksud tidak sesuai dengan RTRW adalah perubahan dari hutan lahan kering primer. Meski masih berstatus sebagai hutan dan berada pada kawasan lindung, tapi perlu dilakukan arahan untuk mempertahankan fungsi hutan dan lahan sehingga produktivitas lahan dan perannya sebagai sistem penyangga kehidupan tetap terjaga. Merujuk pada Peraturan Menteri Kehutanan Nomor : P.70/MenhutII/2008 tentang pedoman teknik rehabilitasi hutan dan lahan maka arahan yang sesuai untuk penggunaan lahan ini berupa kegiatan Rehabilitasi Hutan dan Lahan (RHL). Lebih lanjut (Arsyad et al. 2017) ketidaksesuaian antara penggunaan lahan dengan RTRW pada Kawasan hutan bisa diarahkan untuk kegiatan hutan kemasyarakatan $(\mathrm{HKm})$ dengan sistem agroforestry. Kegiatan ini bertujuan untuk memulihkan, mempertahankan dan meningkatkan fungsi hutan dan lahan sehingga daya dukung, produktivitas dan peranannya dalam mendukung sistem penyangga kehidupan tetap terjaga, hal ini dapat dilakukan dengan cara penanaman multi purpose tree species yang pohonnya tidak di tebang sedangkan buahnya bisa diambil manfaatnya sehingga tidak mengurangi fungsi kawasan tersebut sebagai daerah konservasi tanah dan air seperti tanaman durian ((Durio zibetinus), kemiri dan nangka (Artocarpus spp.).

Pertanian lahan kering yang berada pada kawasan lindung yang dimaksud berupa budidaya tanaman cengkeh (Syzygium aromaticum), kopi (Coffea arabica), coklat (Theobroma cacao), pisang (Musa sp), ubi kayu (Manihot esculenta), dan keladi (Caladium). Untuk mempertahankan fungsi lahan sebagai kawasan konservasi maka perlu ditambahkan tanaman lainnya yang tidak untuk ditebang pohonnya sedangkan buahnya bisa dimanfaatkan oleh masyarakat, baik untuk peningkatan perekonomian atau dikonsumsi sendiri, seperti menanam Durian, Langsat (Lansium domesticum), Rambutan (Nephelium lappaceum). 
Penggunaan lahan semak belukar pada areal hutan lindung untuk arahannya dilakukan upaya suksesi alami dengan pertimbangan bahwa areal tersebut sangat terjal dan susah dijangkau. Dalam kegiatan suksesi alami ini perlu diperhatikan dan dihindari dari berbagai macam gangguan kerusakan sehingga proses suksesi alami dapat berjalan dengan lancar.

Kondisi yang tidak sesuai lainnya berupa pemukiman yang berada pada kawasan lindung. Tanaman yang ada disekitar pemukiman berupa cengkeh (Syzygium aromaticum), dan Kopi (Coffea arabica). Arahan yang dapat dilakukan adalah dengan pengembangan hutan desa yaitu hutan negara yang dikelola oleh desa dan dimanfaatkan untuk kesejahtraan desa serta belum dibebani izin/hak Peraturan Menteri Kehutanan Nomor: P.49/Menhut-II/2008 dan penanaman Multi Purpose Tree Species (MPTS) yaitu tanaman dengan berbagai fungsi. Tanaman cengkeh yang ada disekitar pemukiman disarankan untuk dipadukan dengan tanaman obat-obatan sebagai tumbuhan bawah seperti serai (Cymbopogon citratus), kunyit (Curcuma longa Linn) dan jahe (Zingiber officinale). Sedangkan untuk tanaman kopi disarankan untuk dipadukan dengan tanaman MPTS seperti tanaman Nangka (Artocarpus spp.), Petai (Parkia speciosa), dan Alpukat (Persea americana) sebagai tanaman penaung. Sehingga masyarakat sekitar hutan bisa memanfaatkan jasa lingkungan dan pemungutan hasil tanaman tanpa mengurangi fungsi konservasi lahan, sehingga keduanya bisa saling menguntungkan.

Penggunaan lahan sawah yang tidak sesuai berada pada sempadan sungai. Maka arahan yang dilakukan untuk mencegah terjadinya erosi dan longsor pada tebing sungai berupa penanaman tanaman lokal seperti Bambu (Bambussa sp.), Mangga (Mangifera indica), Pisang (Musa paradisiaca), Lamtoro (Laucaena leucocephala) dan Nangka (Artocarpus heterophyllus) yang berjarak 10 meter dari sungai kemudian membuat bangunan penguat dinding/tebing atau pengaman jurang untuk mencegah terjadinya longsor. Hal ini sejalan dengan penelitian Idjudin (2011) bahwa Pengendalian longsor dapat direncanakan dan diimplementasikan melalui pendekatan mekanis (sipil teknis) dan vegetatif atau kombinasi keduanya. Pada kondisi yang sangat parah, pendekatan mekanis seringkali bersifat mutlak jika pendekatan vegetatif saja tidak cukup memadai untuk menanggulangi longsor.

\section{KESIMPULAN}

Berdasarkan hasil penelitian yang diperoleh, maka dapat ditarik kesimpulan bahwa :

1. Penggunaan lahan di DAS Bialo terdapat tujuh kelas penggunaan lahan yaitu hutan lahan kering primer, hutan lahan kering sekunder, pertanian lahan kering, pemukiman, sawah, semak belukar dan tambak. 
2. Penggunaan lahan yang sesuai dengan pola ruang sebesar $9774,59(87,8 \%)$ dan yang tidak sesuai sebesar $1173,34(12,2 \%)$.

3. Arahan penggunaan/pengelolaan lahan pada kawasan lindung yaitu arahan teknik vegetatif berupa agroforestry, hutan desa, Multi Purpose Tree Species (MPTS) dan pembuatan teras konstruksi baik disertai tanaman penutup tanah dan penguat teras pada penggunaan lahan sawah. Diharapkan arahan tersebut menjadi arahan konservasi tanah dan air dalam DAS Bialo

\section{UCAPAN TERIMA KASIH}

Terima kasih kepada ESRI Indonesia atas lisensi Program ArcGISnya melalui Kerjasama dengan Universitas Hasanuddin yang digunakan dalam penelitian ini.

\section{DAFTAR PUSTAKA}

Arsyad, Usman, Andang Suryana Soma, Wahyuni Wahyuni, and Tita Rahayu Arief. 2017. "Kesesuaian Dan Arahan Penggunaan Lahan Berdasarkan Rencana Pola Ruang Wilayah Di Hulu Daerah Aliran Sungai Kelara.” Jurnal Hutan Dan Masyarakat 9(2):75. doi: 10.24259/jhm.v9i2.2872.

Asyad, Sitanala. 2010. Konservasi Tanah Dan Air. Bogor: IPB PRESS.

Fadilah, Nurul, Usman Arsyad, and Andang Suryana Soma. 2019. "Analisis Tingkat Kerawanan Tanah Longsor Menggunakan Metode Frekuensi Rasio Di Daerah Aliran Sungai Bialo.” Perennial 15(1):42. doi: 10.24259/perennial.v15i1.6317.

Hilmanto, Rudi. 2012. "Optimalisasi Harga Komoditi Agroforestri Untuk Meningkatkan Pendapatan Petani." Jurnal Administrasi Bisnis 1(1):8. doi: https://doi.org/10.14710/jab.v1i1.4293.

Idjudin, A. Abas. 2011. "Peranan Konservasi Lahan Dalam Pengelolaan Perkebunan." Sumber Daya Lahan 5(2):14.

Kementeriaan Lingkungan Hidup dan Kehutanan Republik Indonesia. 2008a."Peraturan Menteri Kehutanan Nomor: P.49/Menhut-II/2008 Tentang Hutan Desa.”

Kementeriaan Lingkungan Hidup dan Kehutanan Republik Indonesia. 2008b."Peraturan Menteri Kehutanan Nomor : P.70/Menhut-II/2008 Tentang Pedoman Teknis Rehabilitasi Hutan Dan Lahan. Jakarta."

Lubis, Suardi, Andri Suprayogi, and Hani Hani'ah. 2013. "Kesesuaian Rencana Tata Ruang Wilayah (RTRW) Dengan Penggunaan Lahan Kecamatan Gayamsari Dan Kecamatan Semarang Timur." Jurnal Geodesi Undip 2(2).

Presiden Republik Indonesia. 1999. Undang-Undang Republik Indonesia Nomor 41 Tahun 1999 Tentang Kehutanan. Jakarta: Sekretariat Kabinet RI.

Presiden Republik Indonesia. 2007. Undang-Undang Republik Indonesia Nomor 26 Tahun 2007 Tentang Penataan Ruang. Jakarta: Sekretariat Kabinet RI. 
Tanika, Lisa, Chandra Irawadi Wijaya, Elissa Dwiyanti, Latar Belakang, and Kalibrasi Validasi. 2013. "Peranan Lahan Berbasis Agroforestri Terhadap Neraca Air Di DAS Bialo , Sulawesi Selatan.” P. 7 in Prosiding Seminar Agroforestri. UGM.

Thomas M. Lillesand, Ralph W. Kiefer. 1993. Lillesand, Thomas M; Dulbahri; Susanto; Kiefer, Ralph W. (1993). Penginderaan Jauh Dan Interpretasi Citra Susanto. Yogyakarta :: Gadjah Mada University Press,. 2nd ed. edited by Dulbahri and Susanto. Yogyakarta: Gadjah Mada University Press. 